\title{
Relationship between internal derangement of the temporomandibular joint and dentofacial morphology in women with anterior open bite
}

\author{
Eun-Sun Byun, ${ }^{a}$ Sug-Joon Ahn, ${ }^{\mathrm{b}}$ and Tae-Woo Kim ${ }^{\mathrm{c}}$ \\ Seoul, Korea
}

\begin{abstract}
Introduction: Anterior open bite is known to be associated with internal derangement of the temporomandibular joint (TMJ). This study examined the relationships between internal derangement and dentofacial morphology in women with anterior open bite. Methods: Fifty-one women with anterior open bite were enrolled in this study. The sample was divided into 3 groups based on magnetic resonance imaging of bilateral TMJs: normal disk position, disk displacement with reduction, and disk displacement without reduction. One-way analysis of variance was used to compare the 3 groups with respect to the cephalometric variables, and Duncan's multiple comparisons were performed the $95 \%$ confidence level to identify the differences among the 3 groups. Results: Internal derangement of the TMJ was much more prevalent in subjects with a more posteriorly rotated mandibular ramus, a smaller mandible, and a greater tendency for a skeletal Class II pattern, although all subjects had an anterior open bite. These patterns were more severe as the internal derangement progressed to disk displacement without reduction. Conclusions: Some cephalometric characteristics, such as a decrease in posterior facial height, decrease in ramus height, and backward rotation and retruded position of the mandible, are associated with TMJ internal derangement in women with anterior open bite. (Am J Orthod Dentofacial Orthop 2005;128:87-95)
\end{abstract}

$\mathbf{I}$ nternal derangement (ID) of the temporomandibular joint (TMJ) is defined as an abnormal relationship of the articular disk to the condyle, fossa, and articular eminence, and is synonymous with disk displacement. ${ }^{1}$ However, perforations between the joint compartments or fibrous adhesions between the articulating surfaces are other examples of TMJ ID. ID is a common form of temporomandibular disorder (TMD). Almost $80 \%$ of adult symptomatic patients and $94 \%$ of pediatric symptomatic patients with TMD have some form of ID. ${ }^{2-5}$

Various imaging techniques can be used to evaluate the temporomandibular joint, such as transcranial radiography, tomography, arthrography, computed tomography, and magnetic resonance imaging (MRI). In particular, MRI shows a high diagnostic accuracy in

From the Dental Research Institute and the Department of Orthodontics, College of Dentistry, Seoul National University.

${ }^{\mathrm{a}}$ Graduate student.

${ }^{\mathrm{b}}$ Assistant professor.

${ }^{\mathrm{c}}$ Associate professor and chairman.

Supported by a grant from the Korea Health 21 R\&D Project, Ministry of Health and Welfare, Republic of Korea (03-PJ1-PG1-CH09-0001).

Reprint requests to: Sug-Joon Ahn, Deptment of Orthodontics, College of Dentistry, Seoul National University, 28-22 Yunkeun-Dong, Chongro-Ku, Seoul 110-768, Korea (ROK); e-mail, titoo@snu.ac.kr.

Submitted, November, 2003; revised and accepted, January, 2004. 0889-5406/\$30.00

Copyright (C) 2005 by the American Association of Orthodontists. doi:10.1016/j.ajodo.2004.01.028 determining the articular disk position related to the condyle and articular eminence. ${ }^{6-8}$ It has been reported that disk displacement can be observed in 5\% to $11.8 \%$ of patients when MRI was used in asymptomatic, juvenile orthodontic patients. ${ }^{9,10}$ In addition, MRI has shown disk displacement in $33 \%$ of asymptomatic volunteers and $84 \%$ of symptomatic patients. ${ }^{3,4}$ All forms of disk displacement are more prevalent in female than in male patients. ${ }^{11}$

Recently, there has been increasing concern about the influence of the TMJ on facial morphology. ID is believed to be a factor that can influence facial morphology. Several studies have assessed the associations between the radiographic depiction of osseous TMJ components and facial morphology in adolescents, ${ }^{12,13}$ associations between clinical signs and symptoms of TMD and malocclusion, ${ }^{14-18}$ morphological features of the condyles as related to malocclusion, ${ }^{19}$ and associations between facial skeletal patterns and MRIs of TMJs. ${ }^{19-22}$

TMJ ID can alter condyle and mandibular morphology, which results in facial changes, ${ }^{22-25}$ but a proper assessment of its association with altered craniofacial morphology_-particularly, women with anterior open bite- has not been performed. Moreover, anterior open bite is reported to be associated with TMJ ID. ${ }^{15,26}$ The aim of this study was to determine the relationship 

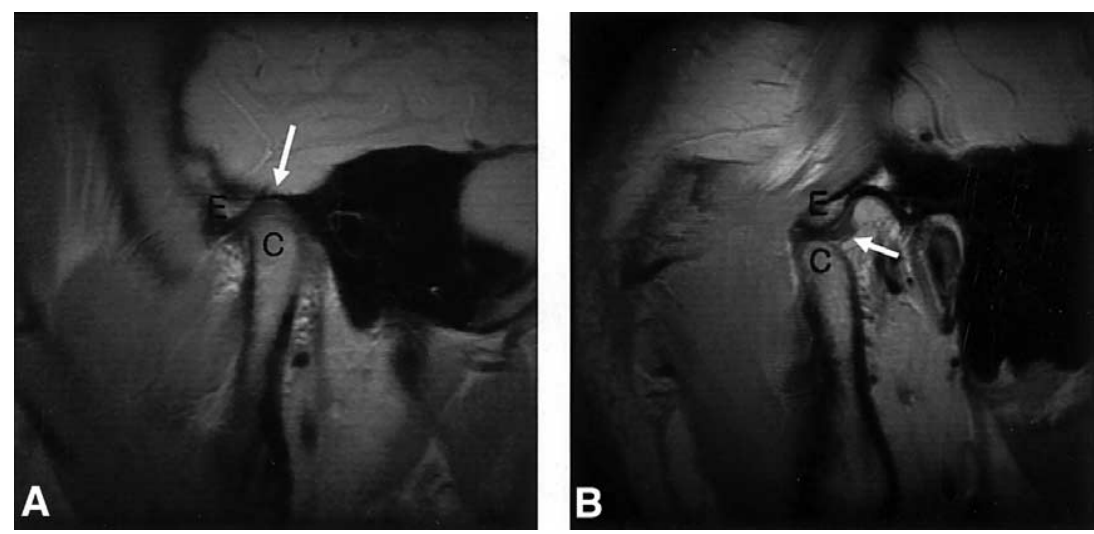

Fig 1. Sagittal images showing normal TMJ disk position to condyle. A, Closed mouth; B, open mouth. Intermediate zone of disk (arrow) was interposed between condyle $(C)$ in both closed- and open-mouth positions.

between TMJ ID and dentofacial morphology in women with anterior open bite.

\section{MATERIAL AND METHODS}

The sample consisted of women over the age of 18 . None of them had previously been diagnosed with juvenile rheumatoid arthritis. Men were not included to avoid skewing the cephalometric measurements with sex-related differences. A total of 124 women consented to the TMJ MRI, and 73 of the subjects with anterior open bite participated in this study. They included some women with clinically detectable TMJ signs and symptoms (capsular pain, joint sounds, masticatory muscle tenderness, limited mandibular range of motion, and deviation on opening), and some without symptoms.

MRIs were obtained by using Signa Horison (GE, Waukesha, Wis) operating at $1.5 \mathrm{~T}$ and a unilateral 3-in surface receiver coil (GE). Initially, axial scout images were obtained at the level of the TMJs to identify the long axes of the condyles. Nonorthogonal sections, both sagittal (perpendicular to the condyles), and coronal oblique, were obtained. Closed-mouth images were obtained at maximum dental intercuspation, and openmouth images were taken at a maximum unassisted vertical mandibular opening by using a Burnett bidirectional TMJ device (Medrad, Pittsburgh, Pa). T1weighted 600/12 (repetition time [TR] ms/echo time [TE] ms) and proton-density 4000/14 (TR ms/TE ms) pulse sequences were performed in the sagittal plane by using a 3-mm slice thickness, a 10-cm field of view, a number of excitations of 2 , and an image matrix of 254 $\times 192$ pixels. T1-weighted 500/12 (TR ms/TE ms) pulse sequence was performed in the coronal plane under the same conditions.
The images were interpreted by a radiologist experienced in interpreting TMJ MRIs and an orthodontist. The TMJ disk position was divided into 3 categories according to the following criteria:

1. Normal disk position (Fig 1). In the closed-mouth position, the intermediate zone of the disk was interposed between the condyle and the posterior slope of the articular eminence, with the anterior and posterior bands equally spaced on either side of the condylar load point.

2. Disk displacement with reduction (DDR) (Fig 2). The disk was anteriorly displaced relative to the posterior slope of the articular eminence and the head of the condyle. However, the disk reduced on mouth- opening.

3. Disk displacement without reduction (DDNR) (Fig 3 ). The disk was anteriorly displaced relative to the posterior slope of the articular eminence and the head of the condyle, but without reduction of the disk on mouth opening.

The position and shape of the disk were evaluated carefully according to the classification criteria for disk position. Some ambiguous cases were excluded in this study.

Among 73 patients with anterior open bite, MRI identified 13 patients with unilateral DDR and normal disk position in the contralateral TMJ. There were 3 patients with 1 DDNR and the other joint with normal disk position. Ten patients had bilateral DDR and 13 had bilateral DDNR. Six patients were identified with unilateral DDR and DDNR in the contralateral TMJ. Twenty-eight patients had normal disk positions bilaterally. Only subjects with bilateral normal disk status or those with bilateral DDR or bilateral DDNR were 

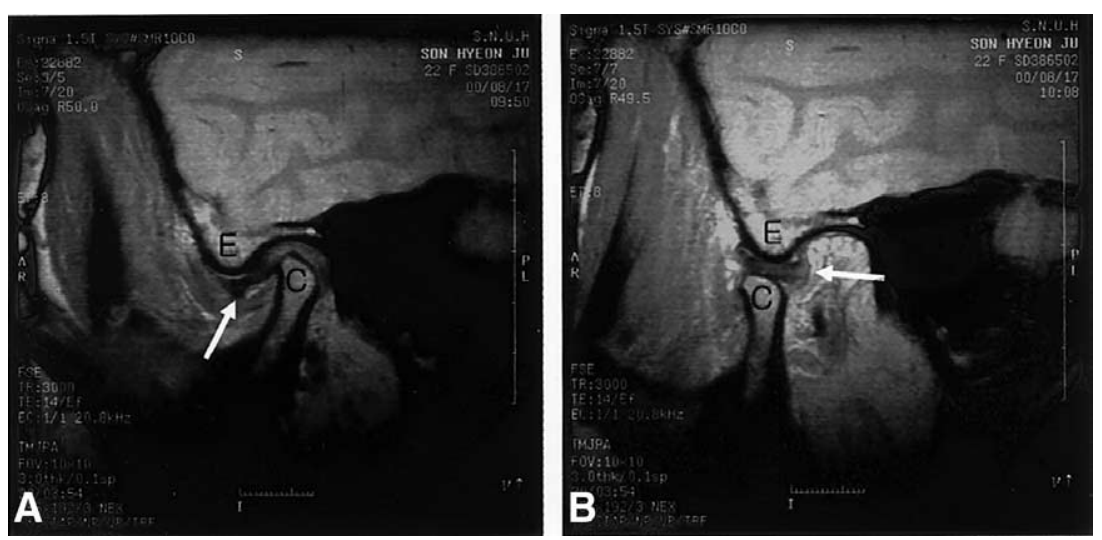

Fig 2. Sagittal images showing disk displacement with reduction to condyle. A, Closed mouth; B, open mouth. Disk (arrow) was displaced anteriorly to posterior slope of articular eminence $(E)$ and head of condyle $(C)$. However, disk was reduced on mouth opening.
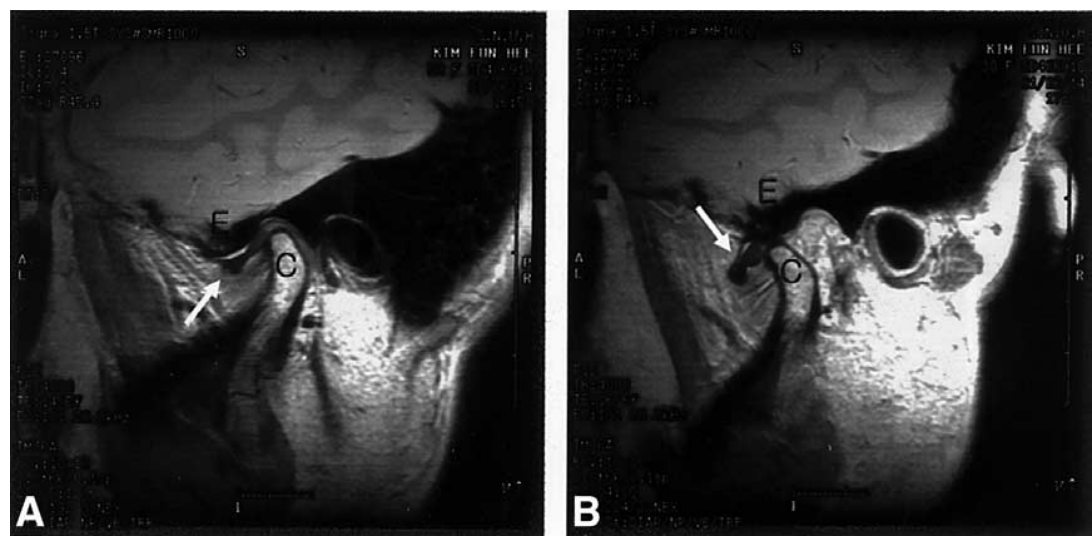

Fig 3. Sagittal images showing disk displacement without reduction to condyle. A, Closed mouth; B, open mouth. Disk (arrow) was anteriorly displaced relative to posterior slope of articular eminence $(E)$ and head of condyle $(C)$, but without reduction of disk on mouth opening.

Table I. Comparison of means and ranges of overbite and age of subjects with normal disk position (group 1), those with disk displacement with reduction (group 2), and those with disk displacement without reduction (group 3)

\begin{tabular}{lccrr}
\hline & $\begin{array}{c}\text { Group 1 } \\
\mathrm{n}=28\end{array}$ & $\begin{array}{c}\text { Group 2 } \\
\mathrm{n}=10\end{array}$ & $\begin{array}{c}\text { Group 3 } \\
\mathrm{n}=13\end{array}$ & $\begin{array}{c}\text { Total } \\
\mathrm{n}=51\end{array}$ \\
\hline Age (yrs) & $23.0 \pm 4.6$ & $23.0 \pm 3.4$ & $24.4 \pm 6.1$ & $23.4 \pm 4.8$ \\
(range) & $(18.2-32.2)$ & $(19.2-30.2)$ & $(18.5-38.9)$ & $(18.2-38.9)$ \\
Overbite (mm) & $-2.5 \pm 1.9$ & $-3.3 \pm 1.7$ & $-3.1 \pm 1.3$ & $6.7 \pm 2.0$ \\
(range) & $(-6.5-0.1)$ & $(-5.9--0.2)$ & $(-4.7--0.2)$ & $(-6.5--0.1)$ \\
\hline
\end{tabular}

included in this study to more accurately evaluate the relationships between progression of ID and facial morphology. The final sample thus consisted of 51 women with anterior open bite between the ages of 18.2 and 38.9 years (Table I).

Lateral cephalometric radiographs were traced on acetate tracing film. The tracings were digitized using a digitizer interfaced with a desktop computer. Twentyone landmarks were digitized on each radiograph, from which 36 cephalometric variables were calculated (Table II). The cephalometric landmarks are illustrated in Figure 4 , and the measurements are illustrated in Figures 5, 6, and 7. One-way analysis of variance (ANOVA) was used to compare the 3 groups with 
Table II. Comparison of cephalometric variables of subjects with normal disk position (group 1), those with disk displacement with reduction (group 2), and those with disk displacement without reduction (group 3)

\begin{tabular}{|c|c|c|c|c|c|}
\hline Variables & $\begin{array}{l}\text { Group } 1 \\
(\mathrm{n}=28)\end{array}$ & $\begin{array}{l}\text { Group } 2 \\
(\mathrm{n}=10)\end{array}$ & $\begin{array}{l}\text { Group } 3 \\
(\mathrm{n}=13)\end{array}$ & Significance & $\begin{array}{c}\text { Multiple } \\
\text { comparisons }^{\dagger}\end{array}$ \\
\hline \multicolumn{6}{|l|}{ Cranial base relationships } \\
\hline Anterior cranial base length $[\mathrm{S}-\mathrm{N}](\mathrm{mm})$ & $68.6 \pm 3.8$ & $68.1 \pm 3.9$ & $66.1 \pm 2.9$ & NS & \\
\hline Posterior cranial base length $[\mathrm{S}-\mathrm{Ar}](\mathrm{mm})$ & $36.1 \pm 4.0$ & $36.7 \pm 2.5$ & $31.9 \pm 4.4$ & $* *$ & $1=2>3$ \\
\hline Saddle angle $[\mathrm{N}-\mathrm{S}-\mathrm{Ar}]\left({ }^{\circ}\right)$ & $125.1 \pm 4.5$ & $124.5 \pm 4.3$ & $122.7 \pm 6.7$ & NS & \\
\hline \multicolumn{6}{|l|}{ Maxillomandibular relationships } \\
\hline SNA angle $\left({ }^{\circ}\right)$ & $81.6 \pm 3.2$ & $81.0 \pm 2.4$ & $81.1 \pm 4.3$ & NS & \\
\hline SNB angle $\left({ }^{\circ}\right)$ & $80.1 \pm 4.3$ & $76.4 \pm 3.0$ & $73.9 \pm 4.3$ & $* * *$ & $1>2=3$ \\
\hline A to $\mathrm{N}$ perpendicular (mm) & $1.8 \pm 2.8$ & $1.6 \pm 2.6$ & $2.4 \pm 3.0$ & NS & \\
\hline Pog to $\mathrm{N}$ perpendicular (mm) & $0.7 \pm 8.5$ & $-6.6 \pm 7.4$ & $-11.0 \pm 6.7$ & $* *$ & $1>2=3$ \\
\hline Facial convexity $[\mathrm{N}-\mathrm{A}-\mathrm{Pog}]\left({ }^{\circ}\right)$ & $2.40 \pm 7.9$ & $9.1 \pm 6.0$ & $14.4 \pm 7.1$ & $* * *$ & $1<2=3$ \\
\hline ANB angle $\left({ }^{\circ}\right)$ & $1.5 \pm 3.7$ & $4.6 \pm 2.6$ & $7.3 \pm 2.9$ & $* * *$ & $1<2<3$ \\
\hline Wits appraisal $(\mathrm{mm})$ & $-7.0 \pm 5.7$ & $-0.4 \pm 4.4$ & $0.3 \pm 3.3$ & $* * *$ & $1<2=3$ \\
\hline \multicolumn{6}{|l|}{ Vertical skeletal relationships } \\
\hline FMA $\left(^{\circ}\right)$ & $29.8 \pm 4.8$ & $32.3 \pm 5.2$ & $36.6 \pm 8.5$ & $* *$ & $1<3$ \\
\hline $\mathrm{SN}$ to mandibular plane angle $\left(^{\circ}\right)$ & $39.7 \pm 5.9$ & $42.6 \pm 4.9$ & $47.7 \pm 9.6$ & $* *$ & $1<3$ \\
\hline FH to palatal plane angle $\left({ }^{\circ}\right)$ & $1.1 \pm 3.3$ & $-1.1 \pm 2.8$ & $-1.99 \pm 3.7$ & NS & \\
\hline Maxillomandibular plane angle [ANS-PNS/Go-Me] $\left({ }^{\circ}\right)$ & $28.7 \pm 5.0$ & $33.3 \pm 6.8$ & $38.6 \pm 9.0$ & $* * *$ & $1=2<3$ \\
\hline Occlusal plane to mandibular plane angle $\left(^{\circ}\right)$ & $19.7 \pm 3.9$ & $22.6 \pm 4.3$ & $22.9 \pm 5.5$ & NS & \\
\hline Total anterior facial height $[\mathrm{N}-\mathrm{Me}](\mathrm{mm})$ & $135.3 \pm 4.6$ & $134.8 \pm 7.3$ & $131.7 \pm 4.3$ & NS & \\
\hline Total posterior facial height $\{\mathrm{S}-\mathrm{Go}\}(\mathrm{mm})$ & $84.7 \pm 6.3$ & $82.7 \pm 6.6$ & $76.4 \pm 6.3$ & $* *$ & $1>3$ \\
\hline Lower anterior facial height [ANS-Me] (mm) & $77.5 \pm 4.4$ & $78.9 \pm 5.8$ & $78.3 \pm 5.4$ & NS & \\
\hline Total anterior facial height/total posterior facial height (\%) & $62.6 \pm 4.7$ & $61.4 \pm 3.8$ & $58.1 \pm 6.0$ & $*$ & $1>3$ \\
\hline Lower anterior facial height/total anterior facial height (\%) & $55.1 \pm 1.8$ & $54.7 \pm 2.5$ & $53.8 \pm 2.2$ & NS & \\
\hline \multicolumn{6}{|l|}{ Size and form of mandible } \\
\hline Ramus height $[\mathrm{Ar}-\mathrm{Go}](\mathrm{mm})$ & $51.7 \pm 4.9$ & $48.1 \pm 5.5$ & $45.8 \pm 3.7$ & $* *$ & $1>3$ \\
\hline Ramus inclination [SN to $\mathrm{Ar}-\mathrm{Go}]$ & $95.1 \pm 6.1$ & $99.5 \pm 7.7$ & $103.0 \pm 6.0$ & $* * *$ & $1<3$ \\
\hline Mandibular body length [Go-Me] (mm) & $78.9 \pm 4.0$ & $75.3 \pm 4.8$ & $71.8 \pm 4.8$ & $* * *$ & $1>3$ \\
\hline Effective mandibular length [Ar-Pog] (mm) & $116.8 \pm 6.4$ & $110.0 \pm 8.4$ & $104.7 \pm 4.9$ & $* * *$ & $1>2>3$ \\
\hline Anterior cranial base/Mandibular body length (\%) & $115.3 \pm 7.7$ & $110.9 \pm 6.8$ & $108.8 \pm 6.7$ & * & $1>2=3$ \\
\hline Gonial angle [Ar-Go-Me $]\left({ }^{\circ}\right)$ & $124.7 \pm 6.1$ & $123.2 \pm 7.8$ & $124.7 \pm 8.9$ & NS & \\
\hline Articular angle $[\mathrm{S}-\mathrm{Ar}-\mathrm{Go}]\left(^{\circ}\right)$ & $150.1 \pm 7.3$ & $155.0 \pm 8.4$ & $160.2 \pm 8.8$ & $* *$ & $1<3$ \\
\hline \multicolumn{6}{|l|}{ Dental relationships } \\
\hline Maxillary incisor to $\mathrm{FH}$ plane $\left(^{\circ}\right)$ & $120.4 \pm 6.2$ & $123.2 \pm 6.4$ & $118.1 \pm 9.1$ & NS & \\
\hline Mandibular incisor to $\mathrm{FH}$ plane $\left({ }^{\circ}\right)$ & $60.7 \pm 11.2$ & $49.7 \pm 4.8$ & $48.0 \pm 5.4$ & $* * *$ & $1>2=3$ \\
\hline Interincisal angle $\left({ }^{\circ}\right)$ & $120.2 \pm 11.7$ & $106.5 \pm 6.8$ & $109.9 \pm 11.7$ & $* *$ & $1>2=3$ \\
\hline Mandibular incisor to mandibular plane angle $\left({ }^{\circ}\right)$ & $89.5 \pm 10.7$ & $98.0 \pm 4.5$ & $95.3 \pm 6.5$ & $*$ & $1<2=3$ \\
\hline Mandibular incisor to A-Pog (mm) & $6.3 \pm 4.4$ & $3.8 \pm 3.9$ & $1.0 \pm 3.6$ & $* *$ & $1>3$ \\
\hline Overbite $(\mathrm{mm})$ & $-2.5 \pm 2.0$ & $-3.3 \pm 1.7$ & $-3.1 \pm 1.3$ & NS & \\
\hline Overjet (mm) & $1.3 \pm 3.0$ & $4.8 \pm 2.6$ & $6.5 \pm 2.5$ & $* * *$ & $1<2=3$ \\
\hline \multicolumn{6}{|l|}{ Soft tissue relationships } \\
\hline Ricketts E-line to upper lip (mm) & $-1.6 \pm 3.2$ & $2.0 \pm 1.5$ & $3.3 \pm 4.0$ & $* * *$ & $1<2=3$ \\
\hline Ricketts E-line to lower lip (mm) & $1.2 \pm 2.7$ & $3.4 \pm 1.8$ & $4.7 \pm 4.5$ & $* *$ & $1<3$ \\
\hline
\end{tabular}

$N S$, Not significant.

$* P<.05 ; * * P<.01 ; * * * P<.001 . \dagger$ Duncan's multiple comparisons were performed at level of $\alpha=0.05$.

respect to all cephalometric measurements. A difference with a $P$ value less than .05 was considered significant. Duncan's multiple comparisons were performed to identify differences between the groups.

Duplicate determinations were performed on 15 cephalometric radiographs, from which the measurement error was calculated by intraclass correlation coefficient. The reliability of tracing, landmark identification, and analytical measurements had intraclass correlation coefficients greater than 0.91 .
A skeletal profile diagram was constructed by using 12 selected cephalometric landmarks measured in terms of the x-y coordinates (Fig 8). The x-axis was constructed parallel to the Frankfort horizontal through sella turcica (S), and the $y$-axis was perpendicular to the $\mathrm{x}$-axis through $\mathrm{S}$. The anteroposterior and vertical displacements of these cephalometric landmarks were measured on the original $\mathrm{x}-\mathrm{y}$ coordinate system, and the average skeletal profile of each group was constructed. The overall tracings were then superimposed on the $\mathrm{x}$-axis at $\mathrm{S}$. 


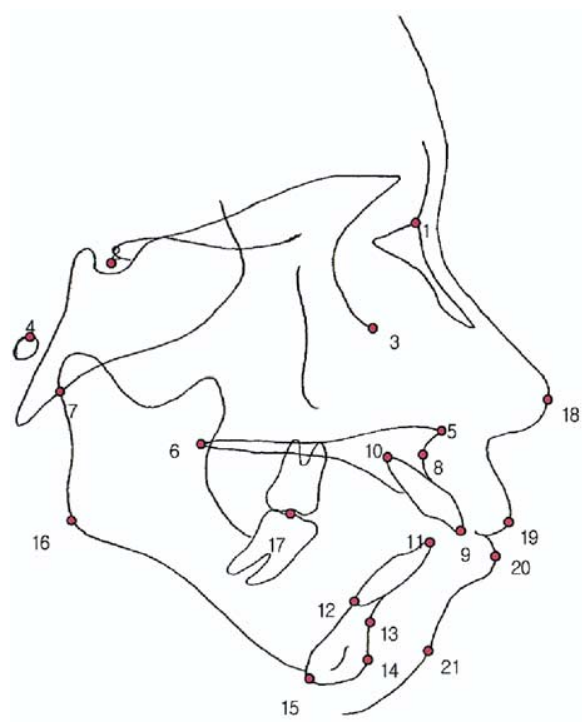

Fig 4. Landmarks used in study: 1, nasion; 2, sella; 3, orbitale; 4 , porion; 5 , anterior nasal spine; 6 , posterior nasal spine; 7, articulare; 8, A-point; 9, incisal end of maxillary incisor; 10, apex of maxillary incisor; 11, incisal end of mandibular incisor; 12, apex of mandibular incisor; 13, B-point; 14, pogonion; 15, menton; 16, gonion; 17, articulation of maxillary and mandibular molars; 18, pronasale; 19, upper lip; 20, lower lip; 21, soft tissue pogonion.

\section{RESULTS}

Table II lists the differences in cephalometric measurements among the subjects with normal disk position, DDR, and DDNR. ANOVA demonstrated many statistically significant differences among the 3 groups. This indicates that there is a relationship between the change in facial morphology and TMJ ID in women with anterior open bite. In particular, dentofacial morphology of subjects with normal disk position differed significantly from those with DDNR.

In this study, a reduction in posterior cranial base length (S-Ar) was associated with TMJ ID; the anterior cranial base length among the 3 groups was similar. This is supported by a previous study showing the length of S-Ar to have a negative association with increased measures of ID. ${ }^{25}$

Regarding the relationship between the maxilla and the mandible, subjects with TMJ ID had a significantly lower SNB angle than those with normal disk position. Subjects with DDNR also had greater ANB angle, facial convexity, and Wits appraisal than those with normal disk position and DDR. In particular, ANB angle could discriminate between the 3 groups. These

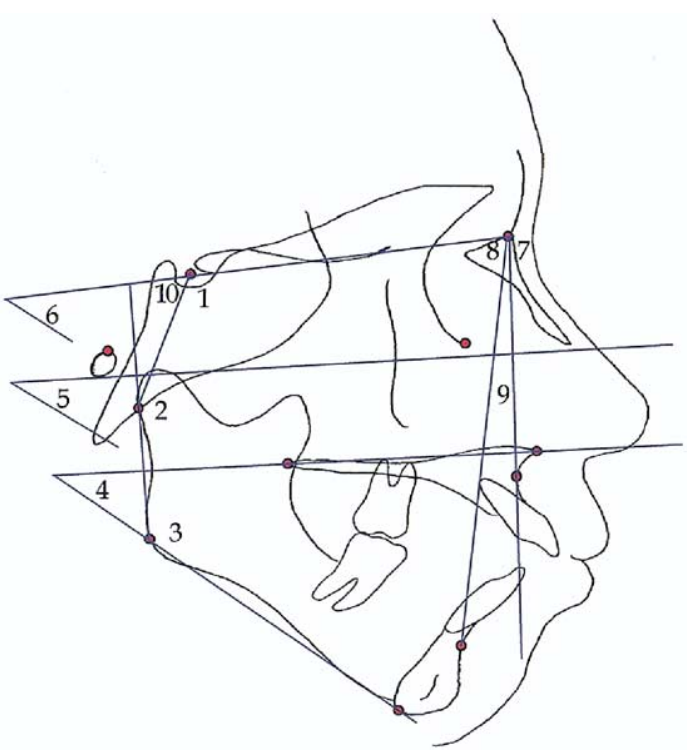

Fig 5. Angular measurements used in study: 1, saddle angle (Na-S-Ar); 2, articular angle (S-Ar-Go); 3, gonial angle (Ar-Go-Me); 4, maxillomandibular plane angle; 5, Frankfort horizontal $(\mathrm{FH})$ to mandibular plane angle; 6 , SN to mandibular plane angle; 7, SNA angle; 8, SNB angle; 9, ANB angle; 10, ramus inclination (N-S to Ar-Go).

results indicate that subjects with TMJ ID had a skeletal Class II pattern with a retrognathic mandible.

In contrast to maxillomandibular relationships, vertical relationships can discriminate mainly between subjects with DDNR and normal disk position. FMA, $\mathrm{SN}$ to mandibular plane angle, and maxillomandibular plane angle were significantly larger in the subjects with DDNR than those with normal disk position. This indicates that subjects with DDNR had steeper mandibular planes. This was caused by the smaller total posterior facial height, because total anterior facial height and lower anterior facial height in the 3 groups were similar.

Among the variables that represent mandibular size and form, all variables except gonial angle showed a statistical significance. Subjects with DDNR showed a smaller ramus height, a larger articular angle, and a smaller mandibular body length than those with normal disk position. Subjects with DDR also showed a similar tendency, but there was no statistical significance. This indicates that the subjects with TMJ ID had a small and posteriorly rotated mandible compared with those with normal disk position.

Dental relationships also showed differences between subjects with normal disk position and TMJ ID. Subjects with TMJ ID had larger overjets and more 


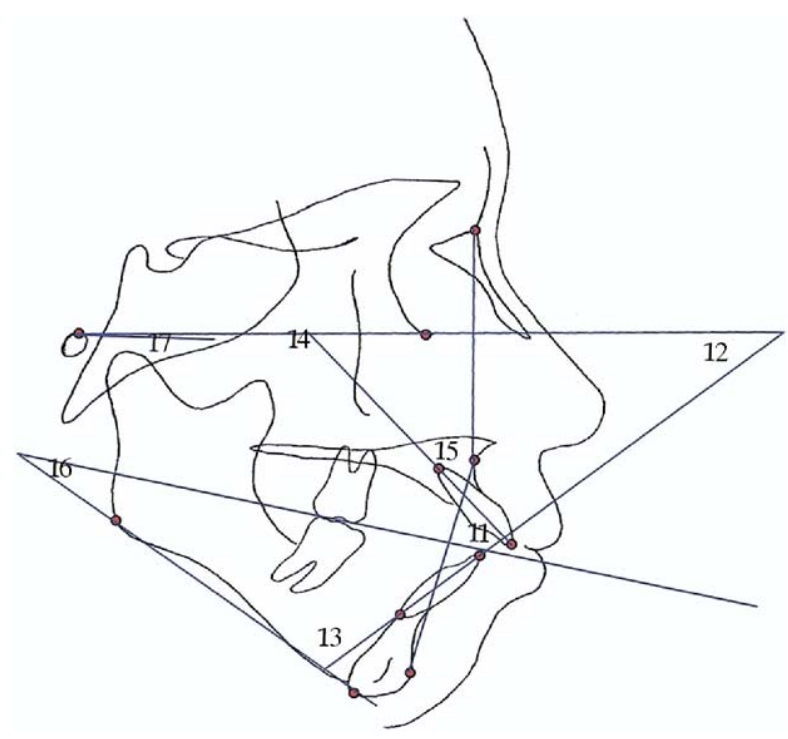

Fig 6. Angular measurements used in study (continued): 11, Interincisal angle; 12, mandibular incisor to $\mathrm{FH}$ plane angle; 13, mandibular incisor to mandibular plane angle; 14, maxillary incisor to $\mathrm{FH}$ plane; 15, facial convexity; 16 , occlusal plane to mandibular plane angle; $17, \mathrm{FH}$ to palatal plane angle.

protrusive mandibular incisors compared with those having normal disk positions. Because all subjects in the study had anterior open bites, overbites in all groups were similar. In soft tissue relationships, subjects with TMJ ID showed protrusive upper and lower lips compared with those having normal disk positions.

Superimposed images of the lateral cephalograms of the 3 groups are shown in Figure 9. These profilograms also demonstrated significant differences in dentofacial morphology in the 3 groups, although the anterior open bite in all subjects had a similar range.

\section{DISCUSSION}

MRI has been used to obtain information on articular disk position within the $\mathrm{TMJ}^{8,27}$ and has provided a direct form of soft tissue visualization with excellent spatial and contrast resolution. ${ }^{27,28}$ In contrast to indirect imaging with arthrography, MRI produces no soft tissue distortion because a contrast medium is not injected into the joint space. ${ }^{29}$ Moreover, MRI is extremely sensitive in identifying TMJ disk displacement and is the only method that directly depicts the disk either in a normal or abnormal position. ${ }^{7,12}$ It also offers many advantages, such as noninvasiveness, minimal pain, minimal risk, and freedom from exposure to ionizing radiation. The aim of this study was to determine which cephalometric variables provide informa-

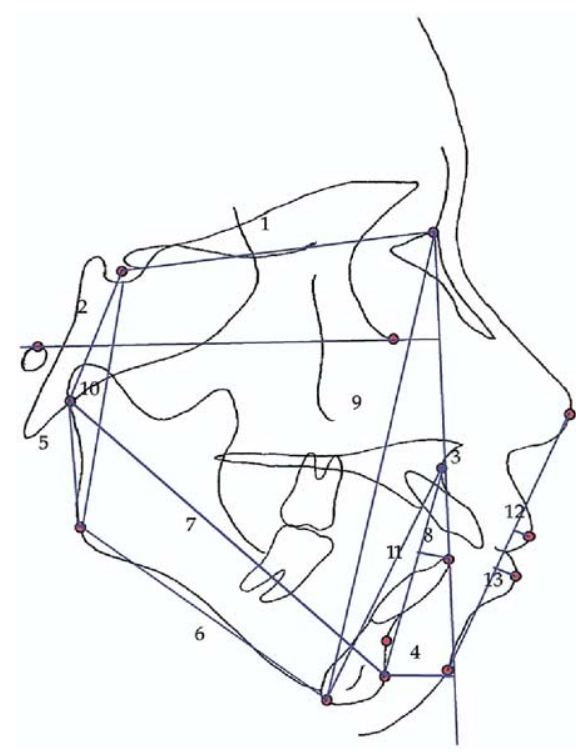

Fig 7. Linear measurements used in study: 1, anterior cranial base length (S-N); 2, posterior cranial base length (S-Ar); 3, N-perpendicular to A-point; 4, N-perpendicular to pogonion; 5 , ramus height (Ar-Go); 6, mandibular body length (Go-Me); 7, effective mandibular length (Ar-Pog); 8, $\mathrm{L} 1$ to A-Pog; 9, total anterior facial height ( $\mathrm{N}-\mathrm{Me}) ; 10$, total posterior facial height (S-Go); 11, lower anterior facial height (ANS-Me); 12, upper lip thickness (Ricketts' E-line); 13, lower lip thickness (Ricketts' E-line).

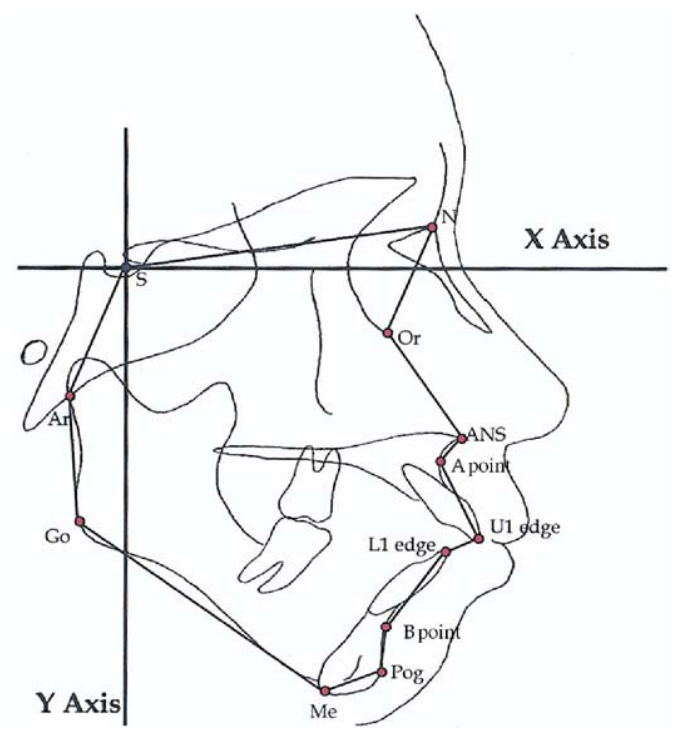

Fig 8. Skeletal profile diagram with 14 representative landmarks.

tion on TMJ ID in women with anterior open bite, using MRI as the gold standard.

According to Schellhas et al, ${ }^{19}$ there is a causal relationship between TMJ ID and an abnormal facial 


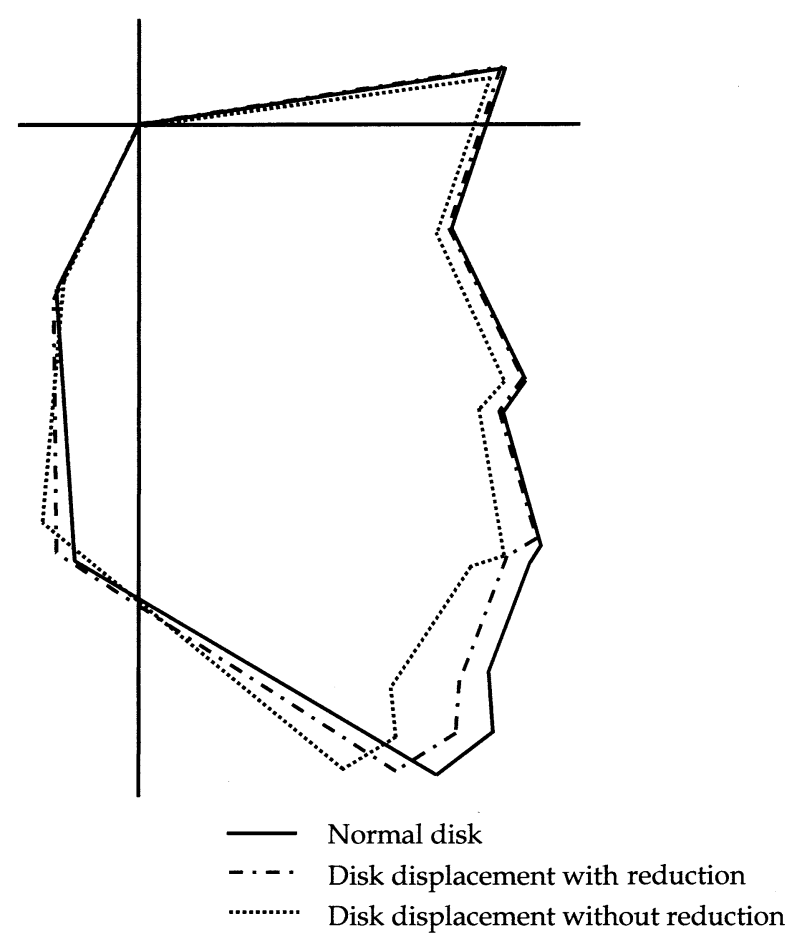

Fig 9. Comparison of skeletal profile diagrams among subjects with normal disk position, DDR, and DDNR. Subjects with TMJ disk displacement had more posteriorly rotated mandibular rami, steeper mandibular planes, and greater tendencies for skeletal Class II patterns than those with normal TMJs. These changes were more severe as ID progressed.

skeleton, which is characterized primarily by a retrognathic mandible, mandibular asymmetry, and occlusal instability. However, Brand et $\mathrm{al}^{21}$ found no distinct relationship between morphologic features of the face and ID of the TMJ. These different conclusions are probably the result of different methods of sample selection. For example, Schellhas et $\mathrm{al}^{19}$ included patients with an externally visible mandibular deformity. More recent studies suggest that TMJ ID is associated with an altered facial morphology. Adolescents with TMJ ID showed decreased ramus and facial heights and posterior rotation of the ramus and mandibular plane. ${ }^{30,31}$ These studies indicate that facial morphology with TMJ ID is related to the skeletal open bite tendency. In contrast to previous studies, the subjects of our study were restricted to women with anterior open bite, who have a high possibility of potential ID. Subdividing the malocclusion patients, as performed in this study, increases the ease and accuracy of investigating the association between disk displacement and dentofacial morphologic changes.

TMJ ID might be related to the change in mandib- ular morphology, because the size and form of the mandible were significantly different between subjects with TMJ ID and those with normal disk position (Table II). Only the gonial angle was not significantly different. Subjects with TMJ ID generally had small and posteriorly rotated mandibles compared with those having normal disk positions. The changes were more pronounced in the subjects with DDNR than those with DDR. The subjects with DDNR had the least mandibular length, least ramus height, and most posteriorly rotated ramus.

Subjects with TMJ ID had small SNB angles, small pogonion to $\mathrm{N}$ perpendicular lengths, large ANB angles, large Wits appraisals, and large facial convexity, which indicates a skeletal Class II relationship with retrognathic mandible. In addition, subjects with DDNR showed a steep mandibular plane because of decreased total posterior facial height. This change in dentofacial morphology might be associated with mandibular morphology. A reduction in mandibular body length and effective mandibular length has been associated with skeletal Class II and retrognathic mandible, whereas posterior rotation of the mandibular ramus and reduction in ramal height have been associated with a reduction in total posterior facial height and steep mandibular plane. However, in our study, the anteroposterior position of the maxilla was similar in all 3 groups (Table II). This is consistent with previous studies, which have been performed on adolescent samples and patients with TMJ symptoms. ${ }^{22-25,35}$

Dental and soft tissue relationships also support the relationship between TMJ ID and dentofacial morphology. The subject with TMJ ID had a protrusive mandibular incisor, protrusive upper and lower lips, and a large overjet compared with those having normal disk position. The protrusive mandibular incisor might be due to dental compensation of that tooth as a result of a skeletal Class II tendency. The protrusive upper and lower lips might also be related to the retrognathic position and backward rotation of the mandible. A large overjet also indicates a skeletal Class II tendency with a retrognathic mandible in subjects with TMJ ID.

This study showed that anterior open bite might be associated with ID, because normal TMJs were not found frequently in TMJ ID patients with anterior open bite. Among 73 women with anterior open bite, only 28 had bilateral normal disk positions. Even though all subjects in this study had anterior open bites, there was a statistically significant difference in sagittal and vertical skeletal relationships between subjects with normal disk positions and TMJ ID, which was much more prevalent in subjects with characteristic dentofacial findings, such as a more posteriorly rotated ramus, 
steeper mandibular plane, and smaller mandible. The subjects with DDNR showed the greatest dentofacial change compared with those having DDR and normal disk position. These results indicate that TMJ ID is associated mainly with a Class II vertical skeletal pattern having anterior open bite. The changes in skeletal profiles according to the state of TMJ ID are illustrated in Figure 9.

A cause-and-effect relationship between TMJ ID and altered craniofacial morphology is uncertain in subjects with anterior open bite, even though associations between ID and altered craniofacial morphology have been shown. It is possible that TMJ ID might have been the result of the skeletal pattern with a posteriorly rotated ramus and short mandible in the subjects with anterior open bite. In contrast, alterations in disk position can cause such dentofacial changes, because TMJ ID affects the normal physiology of the condyle. ${ }^{32,33}$ Recent evidence has indicated that TMJ disk displacement might cause dentofacial changes approaching a severe Class II open bite. ${ }^{34}$ However, this study showed that TMJ ID was less prevalent in subjects with a normal or Class III skeletal tendency than in those with a skeletal Class II pattern and a small mandible (Table II). This also suggests that a skeletal Class II vertical skeletal pattern with a small mandible might be a risk factor for TMJ ID.

This study showed that there is an evident association between TMJ ID and dentofacial morphology. In addition, this association is not sex specific. ${ }^{25,35} \mathrm{~Pa}$ tients with TMJ ID can have the clinical symptoms irrespective of orthodontic treatment, because ID of the TMJ might be sufficient to disturb the normal adaptive capacity, resulting in loss of condylar equilibrium. Therefore, regardless of the cause-effect relationship, it is important to screen out patients with TMJ ID before beginning orthodontic treatment, because TMJ signs and symptoms during or after treatment might be interpreted to be a result of the treatment. However, MRI is too expensive for routine use in identifying TMJ ID. This study indicates that some cephalometric variables could provide sufficient information to distinguish patients with potential ID. It is important to screen patients with anterior open bite and certain characteristic findings, such as a small and retrognathic mandible, posteriorly rotated ramus, and steep mandibular plane angle for TMJ ID.

\section{CONCLUSIONS}

In this study, we evaluated the efficiency of the lateral cephalogram using MRI as the gold standard for identifying TMJ ID in women with anterior open bite. Those with TMJ ID showed a more posteriorly rotated ramus, a steeper mandibular plane, a smaller mandible, and a tendency toward a skeletal Class II pattern, compared with those having normal disk positions. These skeletal patterns were more severe as TMJ ID progressed to DDNR by way of DDR. This study suggests that there is an association between TMJ disk displacement and dentofacial morphology, even though the subjects have anterior open bite.

\section{REFERENCES}

1. Dolwick MF, Riggs RR. Diagnosis and treatment of internal derangement of the temporomandibular joint. Dent Clin North Am 1983;27:561-72.

2. Paesani D, Westesson PL, Hatala M, Tallents RH, Kurita K. Prevalence of temporomandibular joint internal derangement in patients with craniomandibular disorders. Am J Orthod Dentofacial Orthop 1992;101:41-7.

3. Katzberg RW, Westesson PL, Tallents RH, Drake CM. Anatomic disorders of the temporomandibular joint disk in asymptomatic subjects. J Oral Maxillofac Surg 1996;54:147-53.

4. Tallents RH, Katzberg RW, Murphy W, Proskin H. Magnetic resonance imaging findings in asymptomatic volunteers and symptomatic patients with temporomandibular disorders. J Prosthet Dent 1996;75:529-33.

5. Katzberg RW, Tallents RH, Hayakawa K, Miller TL, Goske MJ Wood BP. Internal derangement of the temporomandibular joint: findings in the pediatric age group. Radiology 1985;154:125-7.

6. Westesson PL. Structural hard-tissue changes in temporomandibular joint with internal derangement. Oral Surg Oral Med Oral Pathol 1985;59:220-4.

7. Westesson PL. Reliability and validity of imaging diagnosis of temporomandibular joint disorder. Adv Dent Res 1993;7:137-51.

8. Tasaki MM, Westesson PL. Temporomandibular joint: diagnostic accuracy with sagittal and coronal MR imaging. Radiology 1993;186:723-9.

9. Hans MG, Lieberman J, Goldberg J, Rosencweig G, Bellon E. A comparison of clinical examination, history, and magnetic resonance imaging for identifying orthodontic patients with temporomandibular joint disorders. Am J Orthod Dentofacial Orthop 1992;101:54-9.

10. Lieberman JM, Hans MG, Rozencweig G, Goldberg HS, Bellon EM. MR Imaging of the juvenile temporomandibular joint: preliminary report. Radiology 1992;182:531-4.

11. Nebbe B, Major PW. Prevalence of TMJ disk displacement in a pre-orthodontic adolescent sample. Angle Orthod 2000;70:454-63.

12. Stringert HG, Worms FW. Variations in skeletal and dental patterns in patients with structural and functional alterations of the temporomandibular joint: a preliminary report. Am J Orthod 1986;89:285-97.

13. Dibbets JM, van der Weele LT. Prevalence of TMJ symptoms and X-ray findings. Eur J Orthod 1989;11:31-6.

14. Meng HP, Dibbets JMH, van der Weele LT, Boering G. Symptoms of temporomandibular joint dysfunction and predisposing factors. J Prosthet Dent 1987;57:215-22.

15. Riolo ML, Brandt D, TenHave TR. Associations between occlusal characteristics and signs and symptoms of TMJ dysfunction in children and young adults. Am J Orthod Dentofacial Orthop 1987;92:467-77.

16. Egermark-Eriksson I, Carlsson GE, Magnusson T, Thilander B. A longitudinal study on malocclusion in relation to signs and 
symptoms of craniomandibular disorders in children and adolescents. Eur J Orthod 1990;12:399-407.

17. Tallents RH, Catania J, Sommers E. Temporomandibular joint findings in pediatric populations and young adults: a critical review. Angle Orthod 1991;61:7-16.

18. Dibbets JM, van der Weele LT. Signs and symptoms of temporomandibular disorders (TMD) and craniofacial form. Am J Orthod Dentofacial Orthop 1996;110:73-8.

19. Schellhas KP, Pollei SR, Wilkes CH. Pediatric internal derangements of the temporomandibular joint: effect on facial development. Am J Orthod Dentofacial Orthop 1993;104:51-9.

20. Schellhas KP, Piper MA, Omile MR. Facial skeleton remodeling due to temporomandibular joint degeneration: an imaging study of 100 patients. Am J Neuroradiol 1990;11:541-51.

21. Brand JW, Nielson KJ, Tallents RH, Nanda RS, Currier GF, Owen WL. Lateral cephalometric analysis of skeletal patterns in patients with and without internal derangement of the temporomandibular joint. Am J Orthod Dentofacial Orthop 1995;107: 121-8.

22. Gidarakou IK, Tallents RH, Kyrkanides S, Stein S, Moss ME. Comparison of skeletal and dental morphology in asymptomatic volunteers and symptomatic patients with bilateral degenerative joint disease. Angle Orthod 2003;73:71-8.

23. Gidarakou IK, Tallents RH, Kyrkanides S, Stein S, Moss ME. Comparison of skeletal and dental morphology in asymptomatic volunteers and symptomatic patients with bilateral disk displacement with reduction. Angle Orthod 2002;72:541-6.

24. Gidarakou IK, Tallents RH, Kyrkanides S, Stein S, Moss ME. Comparison of skeletal and dental morphology in asymptomatic volunteers and symptomatic patients with normal temporomandibular joints. Angle Orthod 2003;73:116-20.

25. Nebbe B, Major PW, Prasad NG. Male adolescent facial pattern associated with TMJ disk displacement and reduction in disk length: part II. Am J Orthod Dentofacial Orthop 1999;116:301-7.
26. Imai $\mathrm{T}$, Okamoto $\mathrm{T}$, Kaneko $\mathrm{T}$, Umeda $\mathrm{K}$, Yamamoto $\mathrm{T}$, Nakamura S. Long-term follow-up of clinical symptoms in TMD patients who underwent occlusal reconstruction by orthodontic treatment. Eur J Orthod 2000;22:61-7.

27. Katzberg RW, Westesson PL, Tallents RH, Anderson R, Kurita $\mathrm{K}$, Manzione JV Jr, et al. Temporomandibular joint: MR assessment of rotational and sideways disk displacements. Radiology 1988;169:741-8.

28. Brooks SL, Westesson PL. Temporomandibular joint: value of coronal MR images. Radiology 1993;188:317-21.

29. Cirbus MT, Smilack MS, Beltran J, Simon DC. Magnetic resonance imaging in confirming internal derangement of the temporomandibular joint. J Prosthet Dent 1987;57:488-94.

30. Nebbe B, Major PW, Prasad NG, Grace M, Kamelchuk LS. TMJ internal derangement and adolescent craniofacial morphology: a pilot study. Angle Orthod 1997;67:407-14.

31. Nebbe B, Major PW, Prasad NGN. Adolescent female craniofacial morphology associated with advanced bilateral TMJ disk displacement. Eur J Orthod 1998;20:701-12.

32. Stegenga B, De Bont LG, Boering G, Van Willigen JD. Tissue responses to degenerative changes in the temporomandibular joint: a review. J Oral Maxillofac Surg 1991;49:1079-88.

33. Holmlund AB, Gynther GW, Reinholt FP. Disk derangement and inflammatory changes in the posterior disk attachment of the temporomandibular joint: a histologic study. Oral Surg Oral Med Oral Pathol 1992;73:9-12.

34. Ahn SJ, Kim TW, Nahm DS. Cephalometric keys to internal derangement of temporomandibular joint in women with Class II malocclusions. Am J Orthod Dentofacial Orthop 2004;126:486-95.

35. Nebbe B, Major PW, Prasad NG. Female adolescent facial pattern associated with TMJ disk displacement and reduction in disk length: part I. Am J Orthod Dentofacial Orthop 1999;116: 168-76.

\section{AVAILABILITY OF JOURNAL BACK ISSUES}

As a service to our subscribers, copies of back issues of the American Journal of Orthodontics and Dentofacial Orthopedics for the preceding 5 years are maintained and are available for purchase from Mosby until inventory is depleted. Please write to Elsevier Inc. Subscription Customer Service, 6277 Sea Harbor Dr, Orlando, FL 32887, or call 800-654-2452 or 407-345-4000 for information on availability of particular issues and prices. 